\title{
THE EFFECT OF RELATIVE ENAMEL/DENTIN SHADE THICKNESS ON THE COLOR OUTCOME OF RESIN COMPOSITE SYSTEMS
}

\author{
Ahmed Tarek Metwally*, Ola Fahmy** and Mohamed Abd El Mohsen***
}

\begin{abstract}
This study was conducted to evaluate the effect of relative thickness of different resin composite systems using enamel and dentin shades following the natural layering concept on the final color outcome. Ninety resin composite discs were assigned according to resin composite system into three groups of 30 discs each: Ceram X Duo (S1), Filtek ${ }^{\mathrm{TM}}$ Z350 XT (S2) and Amaris ${ }^{\circledR}(\mathrm{S} 3)$. Each group was divided in to 3 subgroups $(n=10)$ according to the relative Enamel (E) : Dentin (D) thickness in to $0.5 \mathrm{~mm}$ E: $1.5 \mathrm{~mm} \mathrm{D}$ (T1), $1 \mathrm{E}: 1 \mathrm{D}$ (T2), $1.5 \mathrm{E}: 0.5 \mathrm{D}$ (T3) on top of $0.5 \mathrm{~mm}$ thick basic enamel background as a standardized layer simulating the clinical condition. A Vitapan A2 classical shade tab was used as a reference shade to which the different specimens of the three tested systems were compared. Color difference $(\Delta \mathrm{E})$ was measured and calculated using an electronic shade detection device which is VITA Easyshade ${ }^{\circledR}$ Advance 4.0 over a black background. UVShimadzu $3101 \mathrm{pc}$-spectrophotometer was also used in this study to confirm the results obtained by Easyshade Advance 4.0. The results were analyzed by analysis of variance (ANOVA)/Tukey's post hoc test $(\mathrm{p}<0.05) \Delta \mathrm{E}$. All tested composite systems at all thickness showed significant color difference $(\Delta E)$ when compared to each other with the increase of the enamel shade thickness. Although the $\Delta \mathrm{E}$ between S2T1 and A2 shade tab was statistically significant, but clinically not perceptible $(\Delta \mathrm{E}=1.780 \pm 0.1814)$.
\end{abstract}

\section{INTRODUCTION}

Dental esthetics has become increasingly important during the last decade when considering diagnosis and treatment planning. Nowadays, patients seek highly esthetic restorations especially when dealing with the smile zone requiring more sophisticated techniques that meet with their demands. Resin composite today occupies a paramount position among restorative materials because they offer excellent aesthetic potential and acceptable longevity with a much lower cost than equivalent ceramic restorations for the treatment of both anterior and posterior teeth (Macedo et al, in 2006). Having a perfect direct composite restorations using the conventional techniques has become an elusive goal because of the imperfect optical

\footnotetext{
* Teaching Assistant at Operative Dentistry Department, Misr International University

** Professor of Operative Dentistry, Misr International University

*** Professor of Operative Dentistry, Cairo University
} 
properties of the composite resins and the difficulty in obtaining a perfect optical match between mono shaded composites and the tooth structure especially in situations like through and through class III and IV restorations where little or even no existing tooth structure surrounds the restoration which plays an important role in improving the final outcome of the restoration. These drawbacks, essentially related to the complexity of many composite systems, can be overcome today by the application of "the natural layering concept" which makes use of only two basic masses, in which a layer of more translucent enamel shade is often applied over the more opaque dentin shade to create color depth perception from within the restoration to reduce the color coming only from the surface of the restoration creating a highly esthetic direct composite restoration, however these shading concepts used by the manufacturers may be confusing to many clinicians and might prevent a correct application of the different components of the composite systems. Fahmy and Elgandour, in 2006, examined the effect of thickness of dentin and enamel shades on the color of double layered resin composite comparing to the corresponding vita shade which is used as a reference. They concluded that on using layered restorations the enamel thickness should not exceed $1 \mathrm{~mm}$. Paravina et al, in 2006, evaluated color compatibility of corresponding resin composite shades keyed to Vitapan Classical shade guide. They found that poor color compatibility of shade pairs of identical shade designation was recorded. Vichi et al, in 2007, studied the effect of the combination of different shades, opacities and thicknesses on aspects of the final color as a laboratory simulation of a clinical 2-layer stratification technique. They concluded that layer thickness and the proportion of thicknesses of the dentin and translucent shade greatly influence the final aspect of a multi-layer composite restoration. Braun et al, in 2013, assessed a novel aesthetic composite material and the influence of white and black backgrounds. It was concluded that by employing the novel aesthetic composite resin, a minor impact of white and black backgrounds could be observed compared to conventional composites. Since the literature is lacking enough and clear evidence about the influence of the relative thickness variation on the final shade of these materials, so the aim of this study was to evaluate the effect of relative thickness on the color using different resin composite systems following the natural layering concept.

\section{MATERIAL AND METHODS}

\section{Materials:}

Three different composite systems were used in this study using enamel and dentin shades, based on nanotechnology, with different thickness following the natural layering concept to provide a vita classic at A2 shade according to the manufacturer recommendation (Table 1).

Table (1): Materials of the study:

\begin{tabular}{|c|c|c|}
\hline Material & Shades & $\begin{array}{c}\text { Manufac- } \\
\text { turer }\end{array}$ \\
\hline $\begin{array}{c}\text { Ceram X Duo } \\
\text { Nano Ceramic } \\
\text { Restorative }\end{array}$ & $\begin{array}{c}\text { E2 shade (enamel } \\
\text { shade) and D2 shade } \\
\text { (dentin shade) }\end{array}$ & Dentsply \\
\hline $\begin{array}{c}\text { Filtek }{ }^{\mathrm{TM}} \text { Z350 } \\
\text { XT Universal } \\
\text { Restorative }\end{array}$ & $\begin{array}{c}\text { A2E shade (enamel } \\
\text { shade) and A3D } \\
\text { shade (dentin shade) }\end{array}$ & 3M ESPE \\
\hline Amaris ${ }^{\text {TN }}$ & $\begin{array}{c}\text { TNade (enamel } \\
\text { shade) and O2 shade } \\
(\text { dentin shade) }\end{array}$ & Voco \\
\hline
\end{tabular}

\section{Specimen Buildup}

Three rectangular split copper molds of $5 \mathrm{~cm}$ length, $1 \mathrm{~cm}$ width and $1.5 \mathrm{~cm}$ in height, where each mold has 5 circular holes on two sides with a standardized internal diameter $6.5 \mathrm{~mm}$ and two screws on one side, were constructed to prepare ninety disc shaped resin composite specimens 
with standardized diameter of $6.5 \mathrm{~mm}$ and overall thickness of $2.5 \mathrm{~mm}$ using the different tested resin composite systems in $0.5 \mathrm{~mm}$ thick layering technique utilizing enamel and dentine shades with different relative thicknesses on top of $0.5 \mathrm{~mm}$ thick basic enamel shade background as a standardized layer simulating the clinical condition. The nighty prepared specimens were divided into three main groups (30 specimens each), according to the resin composite system (S) used (S1, S2, S3) where (S1) denotes Ceram X Duo Nano Ceramic Restorative, (S2) denotes Filtek ${ }^{\mathrm{TM}}$ Z350 XT Universal Restorative and (S3) denotes Amaris ${ }^{\circledR}$. Each group was further subdivided in to 3 subgroups (10 specimens each), according to the relative thickness of enamel and dentin shades ( $\mathrm{T}$ ), the ratio of enamel (E): dentin (D) where T1 is $0.5: 1.5$, in T2 is $1: 1$, in T3 1.5:0.5. The color was assessed successively for each specimen following each layer application.

\section{Color Measurement}

The color of each specimen was measured sequentially after curing of each increment on a black background which was mounted on a holder with a distance of $55 \mathrm{~cm}$ away from the bench placed over a gray background sheet. The specimens were placed to be measured using an electronic shade detection device which is VITA Easyshade ${ }^{\circledR}$ Advance 4.0 and expressed in the form of CIE L* $\mathrm{a}^{*} \mathrm{~b}^{*}$ value in which $\mathrm{L}^{*}$ measures the value, $\mathrm{a}^{*}$ measures the color along the red-green axis, and $b^{*}$ measures the color along the yellow-blue axis. An A2 Vitapan Classical shade tab was used as a reference shade to which the different specimens of the three tested systems were compared. The color of the shade guide was measured with the same shade detection device and expressed in the form of CIE L*a*b* value. UV-Shimadzu 3101 pc-spectrophotometer was used to confirm the results obtained by the VITA Easyshade ${ }^{\circledR}$ Advance 4.0. The total color difference between the A2 Vitapan Classical shade tab and the corresponding resin composite discs was calculated using the following formula: $\Delta \mathrm{E}=\left[\left(\Delta \mathrm{L}^{*}\right) 2+\left(\Delta \mathrm{a}^{*}\right)\right.$ $\left.2+\left(\Delta b^{*}\right) 2\right] 1 / 2$.

\section{Statistical Analysis}

Two way-ANOVA was used to study the effect of different resin composite system and relative E:D thickness on mean $\Delta \mathrm{E}$. Tukey's post-hoc test was used for pair-wise comparison between the means when ANOVA test is significant.

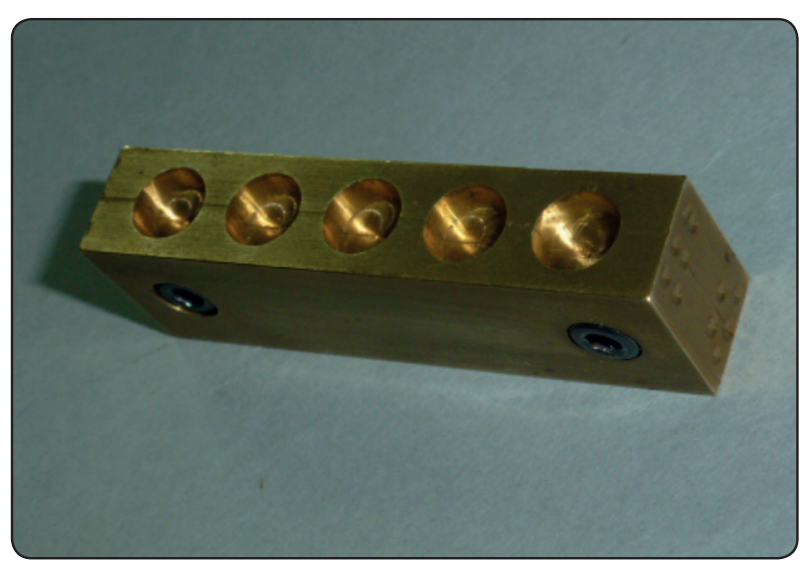

Fig. (1) The copper split mold

\section{RESULTS}

Table 2 and figure 2 represent the effect of different resin composite systems and relative E:D thickness on mean and standard deviation (SD) of $\Delta \mathrm{E}$ in comparison with $\mathrm{A} 2$ Vitaclassic tab. For T1 (0.5:1.5), Amaris ${ }^{\circledR}$ (S3) showed the highest statistical mean $\Delta \mathrm{E}$ followed by Ceram X Duo (S1) followed by Filtek ${ }^{\mathrm{TM}}$ Z350 XT (S2) with significant difference between each other. For T2 (1:1), Ceram $\mathrm{X}$ Duo (S1) showed the highest statistical mean $\Delta \mathrm{E}$ followed by Amaris ${ }^{\circledR}$ (S3) followed by Filtek ${ }^{\mathrm{TM}}$ Z350 XT (S2) with significant difference between each other. For T3 (1.5:0.5), Ceram X Duo (S1) showed the highest statistical mean $\triangle \mathrm{E}$ followed by Amaris ${ }^{\circledR}$ (S3) followed by Filtek ${ }^{\mathrm{TM}}$ Z350 XT (S2) with significant difference between each other.

For Ceram X Duo (S1), T1 showed the lowest statistical mean $\Delta \mathrm{E}$ followed by $\mathrm{T} 2$ followed by 
TABLE (2) Mean and standard deviation (SD) of $\Delta \mathrm{E}$ for different resin composite systems and relative $\mathrm{E}: \mathrm{D}$ thicknesses in comparison with A2 Vitaclassic tab.

\begin{tabular}{|c|c|c|c|c|c|c|c|c|}
\hline & \multirow{3}{*}{$\begin{array}{c}\Delta \mathrm{E} \\
\text { With A2 }\end{array}$} & \multicolumn{6}{|c|}{ Relative E:D thickness (T) } & \multirow{3}{*}{ p-value } \\
\hline & & \multicolumn{2}{|c|}{$\mathrm{T} 1(0.5: 1.5)$} & \multicolumn{2}{|c|}{ T2 (1:1) } & \multicolumn{2}{|c|}{ T3 (1.5:0.5) } & \\
\hline & & Mean & SD & Mean & SD & Mean & SD & \\
\hline \multirow{3}{*}{$\begin{array}{c}\text { Resin } \\
\text { composite } \\
\text { system }(\mathbf{S})\end{array}$} & Ceram X Duo (S1) & $5.63^{\mathrm{bC}}$ & .38 & $8.34^{\mathrm{aB}}$ & .18 & $10.35^{\mathrm{aA}}$ & .20 & $\leq 0.0001 *$ \\
\hline & Filtek $^{\mathrm{TM}}$ Z350 XT (S2) & $1.78^{\mathrm{cC}}$ & .18 & $3.75^{\mathrm{cB}}$ & 0.24 & $6.19^{\mathrm{cA}}$ & .19 & $\leq 0.0001 *$ \\
\hline & $\operatorname{Amaris} \circledast(\mathbf{S 3})$ & $7.11^{\mathrm{aC}}$ & .18 & $8.01^{\mathrm{bB}}$ & .22 & $9.07^{\mathrm{bA}}$ & .21 & $\leq 0.0001 *$ \\
\hline \multicolumn{2}{|r|}{ p-value } & \multicolumn{2}{|c|}{$\leq 0.0001 *$} & \multicolumn{2}{|c|}{$\leq 0.0001 *$} & \multicolumn{2}{|c|}{$\leq 0.0001 *$} & \\
\hline
\end{tabular}

T3 with significant difference between each other. For Filtek $^{\mathrm{TM}}$ Z350 XT (S2), T1 showed the lowest statistical mean $\Delta \mathrm{E}$ followed by $\mathrm{T} 2$ followed by T3 with significant difference between each other. For Amaris ${ }^{\circledR}(\mathrm{S} 3), \mathrm{T} 1$ showed the lowest statistical mean $\Delta \mathrm{E}$ followed by $\mathrm{T} 2$ followed by $\mathrm{T} 3$ with significant difference between each other.

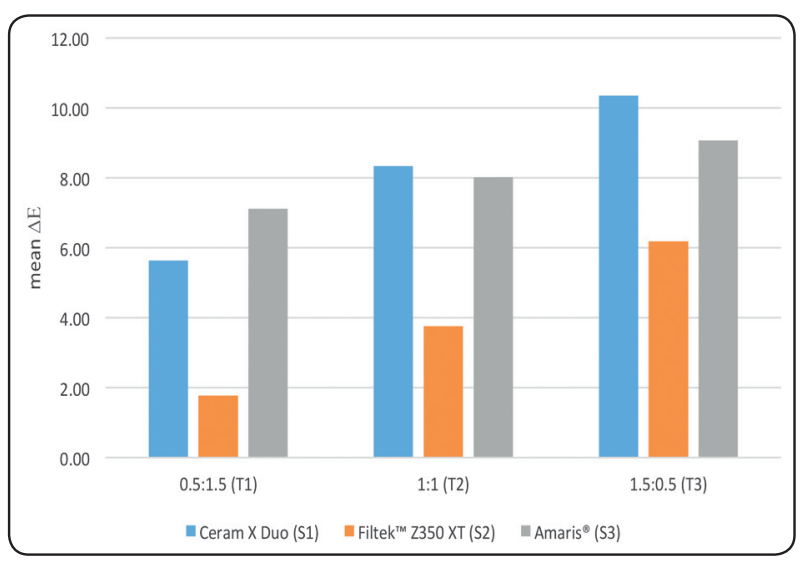

Fig. (2): Histogram showing the mean $\Delta \mathrm{E}$ for different resin composite systems within each relative E:D thickness.

\section{DISCUSSION}

In the current study, three different resin composite systems were used providing A2 shade as a final shade outcome using different enamel and dentin shades. Regarding the color difference with the A2 Vitapan Classical shade tab $(\Delta \mathrm{E})$, according to Fahmy and El ghandour, in 2006 and Da costa et $\mathrm{al}$, in $2010, \Delta \mathrm{E}$ above the acceptability threshold of
3.3 was considered clinically perceptible. Paravina et al, in 2006, Browning et al, in 2009 and Khashayar et al, in 2014, stated that $\Delta \mathrm{E}$ above the acceptability threshold of 3.7 was considered perceptible. The 3 relative E/D thickness in all tested systems showed varied degree of color difference $\Delta \mathrm{E}$, whereas the lowest $\Delta \mathrm{E}$ calculated was $\Delta \mathrm{E}=1.780 \pm 0.18$ and the highest $10.35 \pm 0.20$ (table 2). This finding is showing the tendency of the $\Delta \mathrm{E}$ to increase with the increase of enamel shade thickness in all tested systems. This may be attributed to the changes that occur in the color parameters which affect the final color perception in terms of the $\mathrm{L}^{*}, \mathrm{a}^{*}$ and $\mathrm{b}^{*}$ values which denotes the value, the color along the redgreen axis and the color along the yellow-blue axis, respectively. Differences among different systems may be due to the difference in the chemical and structural composition and physical properties of the tested material in terms of difference in the fillers type, size and content, chemical composition of the resinous matrix, degree of cure of the resin matrix, scattering coefficient, absorption coefficient, light reflectivity, filler distribution in the resinous matrix and difference in refractive index between resin matrix and filler (Lee et al, in 2007 ). All thickness groups of each composite system were above the acceptability threshold except for S2T1 which is considered clinically not perceptible $(\Delta \mathrm{E}=1.780 \pm 0.18)$. The results of the present study were in agreement with Paravina et al, in 2006 who 
evaluated color compatibility of corresponding resin composite shades keyed to Vitapan Classical shade guide. They concluded that there was an overall poor color compatibility of pairs of shades of identical shade disintegration with $\Delta \mathrm{E}$ above 3.7 for most of the shade pairs. Another study by Park and Lee, in 2007, evaluated resin composites and compared enamel and dentin shades with the Vita shade tabs and also found that the great majority of the tested composites did not match the Vita shade tabs. The results also follow Browning et al, in 2009, who showed that no material/shade combination resulted in an acceptable match relative to the used standard of acceptability when various shade tabs of Vitapan Classical shade guides were compared to those made of direct composites. Results from this study and the literature strongly emphasize a need for further color standardization of esthetic dental materials especially resin composite rather than the Vitapan Classical shade guide tabs.

In conclusion, Results from this study and the literature strongly emphasize a need for further color standardization of esthetic dental materials especially resin composite rather than the Vitapan Classical shade guide tabs. Filtek ${ }^{\mathrm{TM}}$ Z350 XT showed comparable results to the Vitapan A2 Classical shade tab when used in the following thickness: $0.5 \mathrm{~mm}$ Enamel: 1.5 Dentin on top of basic enamel thickness layer of 0.5 thickness.

\section{REFERENCES}

1. Braun A, Glockmann A and Krause F. Spectrophotometric evaluation of a novel aesthetic composite resin with respect to different backgrounds in vitro. Journal Odontology 2013; 101:60-66.

2. Browning WD, Contreras-Bulnes R, Brackett MG and Brackett WW. Color differences: polymerized composite and corresponding Vitapan Classical shade tab. Journal of Dentistry 2009; 37:e34-9.

3. Da costa J, Fox P and Ferracane J. Comparison of Various Resin Composite Shades and Layering Technique with a Shade Guide. J Esthet Restor Dent 2010; 22:114-126.

4. Fahmy $\mathrm{O}$ and Elghandour I. Influence of the relative dentin/enamel shade thickness on the color characteristics of a double layered nano composite. J Egyptian Dental Association 2006; 52: 2357-2365.

5. Khashayar G, Dozic A, Kleverlaan C, Feilzer A and Roeters J. The influence of varying layer thicknesses on the color predictability of two different composite layering concepts. Dent Mater 2014; 30 : 493-498.

6. Macedo G, Raj V and Ritter A V. Longevity of anterior composite restorations. J Esthet Restor Dent 2006; $18: 310-311$

7. Paravina R, Kimura M and Powers J. Color compatibility of resin composites of identical shade designation. Quintessence Int 2006; 37:713-719.

8. Vichi A, Fraioli A, Davidson C and Ferrari M. Influence of thickness on color in multi-layering technique. Dent Mater 2007; 23(12):1584-9. 